\title{
The density of surface coating can contribute to different antibacterial activities of gold nanoparticles
}

Le Wang ${ }^{1,2}$, Sixiang $\mathrm{Li}^{2}$, Jiaxiang Yin ${ }^{3}$, Junchuan Yang ${ }^{3}$, Qizhen $\mathrm{Li}^{2}$, Wenfu Zheng $3, *$, Shaoqin Liu ${ }^{1, *}$, Xingyu Jiang ${ }^{1,2 *}$

${ }^{1}$ School of Life Science and Technology, Harbin Institute of Technology, 2 Yikuang Road, Nangang District, Harbin 150001, P. R. China.

${ }^{2}$ Department of Biomedical Engineering, Southern University of Science and Technology, No. 1088 Xueyuan Rd, Nanshan District, Shenzhen, Guangdong 518055, P. R. China

${ }^{3}$ GBA Research Innovation Institute for Nanotechnology, CAS Key Laboratory for Biomedical Effects of Nanomaterials and Nanosafety, National Center for NanoScience and Technology, No. 11 Zhongguancun Beiyitiao, Beijing 100190, P. R. China

\section{Experimental Section}

Materials

Tetrachloroauric acid $\left(\mathrm{HAuCl}_{4} \cdot 3 \mathrm{H}_{2} \mathrm{O}\right)$, mercaptophenylboronic acid (MBA, Mw =153.99, meta-position (3MBA), para-position (4MBA)), aminophenylboronic acid (ABA, Mw =136.94, ortho-position (2ABA), meta-position (3ABA), para-position (4ABA)), sodium borohydride $\left(\mathrm{NaBH}_{4}\right)$, and Tween 80 were from Sigma (USA). All other chemicals and solvents were of reagent grade.

\section{Preparation and Characterization of Phenylboronic acid-derivative-modified} AuNPs

We prepared phenylboronic acid-derivative-modified Au NPs by the one-pot synthesis method with the reduction of $\mathrm{HAuCl}_{4} \cdot 3 \mathrm{H}_{2} \mathrm{O}$ by $\mathrm{NaBH}_{4}$ in water. We mixed the solution of small molecules $(0.1 \mathrm{mmol}, \mathrm{ABA}$ or MBA) in $10 \mathrm{~mL}$ double-distilled water, $\mathrm{HAuCl}_{4} \cdot 3 \mathrm{H}_{2} \mathrm{O}(0.1 \mathrm{mmol})$, triethylamine $(50 \mu \mathrm{L})$ and Tween $80(30 \mathrm{mg})$ for 10 min in an ice-water bath. We added $\mathrm{NaBH}_{4}(6 \mathrm{mg}$ dissolved in $2 \mathrm{~mL}$ water $)$ dropwise in the above mixture with vigorous stirring $(1000 \mathrm{rpm})$. The color of the solution turned brown immediately and we kept stirring the solution for an additional $2 \mathrm{~h}$. We synthesized A/M-AuNPs with different mass ratios of 4ABA and 4MBA (75:25, 50:50, 25:75) following the protocol mentioned above. To remove the untreated chemicals, we sequentially dialyzed the solution with a dialysis bag (14 kDa Mw cut-off, Solarbio) for 24 hours. We sterilized the samples through a $0.22 \mu \mathrm{m}$ filter (Millipore) and stored them at $4{ }^{\circ} \mathrm{C}$ for use.

$0.1 \mathrm{mmol} \mathrm{HAuCl}_{4} \cdot 3 \mathrm{H}_{2} \mathrm{O}$ dissolved in $100 \mathrm{~mL}$ double-distilled water was heated to boiling at $600 \mathrm{rpm} .114 \mathrm{mg}$ sodium citrate dissolved in $100 \mathrm{~mL}$ double-distilled water was added into the bottle containing $\mathrm{HAuCl}_{4} \cdot 3 \mathrm{H}_{2} \mathrm{O}$ and stirred for $10 \mathrm{~min}$ at 1500 
rpm to obtain AuNPs (bare AuNPs). We incubated different concentrations of MBA or ABA with the bare AuNPs solution for $12 \mathrm{~h}$ and centrifuged the product at 8000 rpm for 10 min to remove the untreated chemicals.

We characterized the morphologies of AuNPs by transmission electron microscopy (TEM, Tecnai G2 20 S-TWIN, FEI, USA). The TEM is fitted with a field emission electron gun and operated at $200 \mathrm{kV}$ accelerating voltage. The dynamic light scattering (DLS) and Zeta potential analysis of the samples were measured by a Zetasizer Nano ZS (Malvern Company, England). We employed X-ray photoelectron spectroscopy (XPS ESCALAB 250Xi, ThermoFisher Scientific, USA) to characterize the chemical element of the Au NPs composed of ABA, MBA, and both of ABA and MBA with different ratios respectively. We determined the concentrations of all types of AuNPs by measuring elemental gold with inductively coupled plasma analysis (ICP, iCAP 6300, Thermo Fisher Scientific, USA).

\section{Stability of A/M-AuNPs}

In order to evaluate the stability of $\mathrm{A} / \mathrm{M}$-AuNPs, we analyzed the size changes of nanoparticles in different bacterial and cell culture medium. We incubated the A/M-AuNPs with different media at $37^{\circ} \mathrm{C}$ for 12 and $24 \mathrm{~h}$. DMEM and FBS are used as cell culture media. Mueller-Hinton Broth MHB (MHB, Solarbio), Tryptone (Tryptic) Soy Broth (TSB, Solarbio) and LB are used as bacterial media). The variation of the nanoparticle size was determined by dynamic light scattering (Zetasizer Nano ZS, Malvern Instruments, Southborough, UK).

\section{Antibacterial Activity of Phenylboronic acid-derivative-modified AuNPs}

We analyzed the antibacterial activities of phenylboronic acid-derivative-modified $\mathrm{Au}$ NPs by determining the optical density at $600 \mathrm{~nm}\left(\mathrm{OD}_{600 \mathrm{~nm}}\right)$ based on the turbidity of the bacterial suspension. We selected Gram-positive bacteria $\left(\mathrm{G}^{+}\right)$or Gram-negative bacteria (G-) and clinical MDR isolates (e.g., Escherichia coli (E. coli), MDR E. coli, Staphyloccocus aureus $(S . a)$, and $\operatorname{MDR} S . a$ ) as the microbial models to evaluate the antibacterial activities of the Au NPs. We obtained the MDR isolates from Beijing You'an Hospital with the patient's consent, which was approved by the local Ethics Committee. We cultured the bacteria in the Luria-Bertani (LB) medium $(10 \mathrm{~g} / \mathrm{L}$ casein tryptone, $5 \mathrm{~g} / \mathrm{L}$ yeast extract, and $10 \mathrm{~g} / \mathrm{L} \mathrm{NaCl}, \mathrm{pH}=7$ ) at $37^{\circ} \mathrm{C}$. We diluted the $\mathrm{Au}$ NPs or Ampicillin with nutrient broth inoculated with the tested microbe to a final volume of $100 \mu \mathrm{L}$. We observed the minimal inhibitory concentration (MIC) of the AuNPs after $24 \mathrm{~h}$ of incubation at $37^{\circ} \mathrm{C}$. The original bacterial concentration was $1 \times$ $10^{6}$ colony-forming units $(\mathrm{CFU} / \mathrm{mL})$ and we employed disposable Corning 96-well plates (Costar 3599) for the experiments. We diluted the bacteria in LB media and ensured the initial concentration is $10^{5} \mathrm{CFU} / \mathrm{mL}$. In order to directly show the antibacterial properties of different agents, we used Kirby-Bauer disk agar diffusion method with the addition of A/M-AuNPs or antibiotics for $24 \mathrm{~h}$ respectively, and set the sample without any addition as the control group. Bacteria suspensions $\left(1 \times 10^{6}\right.$ $\mathrm{CFU} / \mathrm{mL}$ ) were spread on the agar plates and then the disks were incubated with the bacteria suspensions for $24 \mathrm{~h}$ at $37^{\circ} \mathrm{C}$. We photographed the inhibition zone around 
the disk specimens by ChemiDoc ${ }^{\text {TMXRS }}+$ (Bio-Rad, USA). The inhibition zone around the disk specimens was used to evaluate the antibacterial activity.

\section{Phenylboronic acid-derivative-modified AuNPs-Induced Disruption of Bacteria Cell Membranes}

We evaluated the permeability of bacteria cell membranes in the presence of phenylboronic acid-derivative-modified AuNPs to explain the mechanism of the antibacterial effects. We used propidium iodide (PI) which can stain DNA or RNA specifically to identify dead cells and used SYTO 9 green fluorescent to detect the living cells. We treated $E$. coli and $S$. $a$ with M_AuNPs, A-AuNPs, or A/M-AuNPs (the molar ratio of $\mathrm{ABA}: \mathrm{MBA}=2: 1$ ) at $37^{\circ} \mathrm{C}$ for $4 \mathrm{~h}$ and stained the bacteria with PI and SYTO 9 (LIVE/DEAD Bac-Light Bacterial Viability Kit, Molecular Probes, L-13152,Invitrogen). The samples were observed under a confocal microscopy (Zeiss LSM 710, Germany) excited at wavelengths of $488 \mathrm{~nm}$ or $568 \mathrm{~nm}$ for emission at 530 $\mathrm{nm}$ (green) or $630 \mathrm{~nm}$ (red) respectively.

We incubated the AuNPs-treated E. coli, MDR E. coli, $S$. $a$, or MDR $S$. $a$, at $37{ }^{\circ} \mathrm{C}$ for $4 \mathrm{~h}$ on a shaking bed at $260 \mathrm{rpm}$ to further explore the antibiotic mechanisms of M_AuNPs, A-AuNPs, and A/M-AuNPs. We fixed the nanoparticles-treated bacterial samples with $2.5 \%$ glutaraldehyde and ethanol dehydrated for SEM analysis (30\%, $50 \%, 70 \%, 80 \%, 90 \%, 95 \%$, and $100 \%$, v/v, in water). The TEM samples were fixed with $2.5 \%$ glutaraldehyde and $0.1 \%$ osmic acid, dehydrated by gradient ethanol, and further cut to ultrathin slices and stained with $2 \%$ uranyl acetate and $0.2 \%$ lead citrate.

\section{Effects of LPS and LTA on Antibacterial Properties}

To assess the interactions between various glycolipids and A/M-AuNPs, we mixed the A/M-AuNPs with sLPS (128 $\mu \mathrm{g} / \mathrm{mL}$, exogenous purified from E. coli O111:B4, Sigma), rLPS (128 $\mu \mathrm{g} / \mathrm{mL}$, exogenous purified from E. coli R515 (Re), AdipoGen Life Sciences), or LTA $(128 \mu \mathrm{g} / \mathrm{mL}$, exogenous purified from $S$. a, Sigma), respectively and incubated them at room temperature. We measured the plasma resonance of A/M-AuNPs and the mixture by an UV-Vis spectrophotometer (UV2450, Japan). We characterized the morphology of the mixture by TEM. The DLS and Zeta potential of the samples were measured by a Zetasizer Nano ZS. To display the effect of LPS and LTA on the antibacterial activity of Au NPs, we used Kirby-Bauer disk agar diffusion method. A/M-AuNPs, LPS/A/M-AuNPs and LTA/A/M-AuNPs-incubated diffusion disks were cut into small disks $(5 \mathrm{~mm}$ in diameter). We spread bacteria suspension $\left(1 \times 10^{6} \mathrm{CFU} / \mathrm{mL}\right)$ on an agar plate and then put the incubated disks on the surface. We incubated the disks with the bacteria suspensions for $24 \mathrm{~h}$ at $37{ }^{\circ} \mathrm{C}$, and photographed the inhibition zone around the disk specimens. Further, we tested the effect of LPS and LTA on the antibacterial activity of A/M-AuNPs by the chequer board assay. In brief, we added LPS (0 to $128 \mu \mathrm{g} / \mathrm{mL}$, $50 \mu \mathrm{L}$, diluted along the abscissa) and A/M-AuNPs (0 to $128 \mu \mathrm{g} / \mathrm{mL}, 50 \mu \mathrm{L}$, diluted along the ordinate) into LB medium in a 96-well plate. Subsequently, we added $10 \mu \mathrm{L}$ of $E$. coli or $S$. $a$ suspension to the $100 \mu$ L LPS and A/M-AuNPs mixture. After $24 \mathrm{~h}$ 
of culture, we recorded the MIC values of the mixtures based on the absorbance at $600 \mathrm{~nm}$. We measured the antibacterial effects of combinations of different concentrations of $\mathrm{A} / \mathrm{M}-\mathrm{AuNPs}$ versus different concentrations of LPS or LTA.

\section{Characterization of AuNPs-Bacterial Polysaccharides Interactions by Isothermal Titration Calorimetry (ITC)}

ITC experiments were performed using a Micro-Cal VP-ITC instrument at $25^{\circ} \mathrm{C}$, wherein $300 \mu \mathrm{L}$ of LPS and LTA solution ( $\mathrm{pH} 7$ ) were injected in equal steps of $10 \mu \mathrm{L}$ into $2 \mathrm{~mL}$ of A-AuNPs, M-AuNPs, and A/M-AuNPs, respectively. Unlike in studies on the binding of two molecules in solution (e.g. protein-substrate reaction), where the binding isotherm can be directly plotted against the molar ratio of reactants in solution, the lack of accurate information on the exact surface area of the gold nanoparticles (i.e., number of moles of surface gold atoms) precludes plotting the binding isotherms. Consequently, we used the total volume of gold atoms $(0.2 \mathrm{mM})$ as fixed quantity and we used the data to identify the trends in the $\mathrm{Au}$ NPs-polysaccharide (2 $\mathrm{mM})$ binding behavior.

\section{Calculation of Numbers of ABA and MBA per Unit Area of AuNPs}

We calculate the number of gold atoms and ligands per NPs using reported methods. ${ }^{1}$ The number of gold atoms, $\mathrm{N}_{\mathrm{Au}}=\left(\mathrm{V}_{\mathrm{NP}} \times \mathrm{APF}\right) / \mathrm{V}_{\mathrm{Au}}=\left(4 \pi \mathrm{r}_{\mathrm{NP}}{ }^{3} / 3 \times 0.7405\right) /\left(4 \pi \mathrm{r}_{\mathrm{Au}}{ }^{3} / 3\right)=$ $\left(\mathrm{d}_{\mathrm{NP}} / 2 \mathrm{~nm}\right)^{3} \times 0.7405 /(0.144)^{3}=\left(\mathrm{d}_{\mathrm{NP}} / \mathrm{nm}\right)^{3} \times 31$, where $\mathrm{V}_{\mathrm{NP}}$ is the volume of a sphere AuNPs, $V_{\mathrm{Au}}$ is the volume of a gold atom, APF is atomic packing factor, $\mathrm{r}_{\mathrm{NP}}$ and $\mathrm{d}_{\mathrm{NP}}$ are the radius and the diameter of a sphere AuNPs, and $r_{A u}$ is the radius of a gold atom. The number Ns of thiolate ligands per NPs, Ns $=\mathrm{N}_{\mathrm{Au}} \times \mathrm{X}, \mathrm{X}$ is the molar ratio of $\mathrm{S}$ or $\mathrm{N}$ to $\mathrm{Au}$ in NPs. The area of gold nanoparticles is calculated as: $\mathrm{S}=4 \pi \mathrm{r}_{\mathrm{NP}}{ }^{2}$.

\section{Biological Safety and Toxicity Evaluation}

BALB/c mice (SPF grade, female, $\sim 20 \mathrm{~g}$ ) were used to evaluate the toxicity of the A/M-AuNPs. 90 mice were divided into six groups $(n=15)$ randomly. We intravenously injected the A/M-AuNPs with different concentrations as the experimental group and injected the saline as controls. We count the survival rate of mice.

\section{Animal Model and Histological Analysis}

We developed acute peritonitis mouse model to evaluate the in vivo treatment effect of A/M-AuNPs. $150 \mathrm{BALB} / \mathrm{c}$ mice were chosen and randomly divided into 6 groups (n $=25)$. We cultured the bacteria in exponential growth phase and resuspended $S . a(1 \times$ $\left.10^{6}\right)$, MDR S. $a\left(5 \times 10^{6}\right)$, E. coli $\left(1 \times 10^{6}\right)$ and MDR E. coli $\left(1 \times 10^{6}\right)$ in the LB medium after washing them with PBS. Serial diluted bacterial suspension were mixed the with $5 \mathrm{wt} \%$ yeast solution in equal volumes. The lowest concentration of bacteria that can kill $100 \%$ of the mice, namely minimum lethal dose (MLD), ${ }^{2}$ was utilized to build the acute peritonitis mouse model. We injected $500 \mu \mathrm{L}$ the mixed bacteria solution into the peritoneal cavity of the mice. One hour later, the mice were in low spirits, rolled up together, and excreted mucous stool, indicating the acute peritonitis 
models were successfully built. We injected A/M-AuNPs with different concentrations into the abdominal cavity of the mice ( 25 mice per group), and injected sterilized saline as a negative control and Ampicillin as a positive control after $1 \mathrm{~h}$ and $6 \mathrm{~h}$. We observed the states of the mice for $72 \mathrm{~h}$ to evaluate their survival.

\section{Animal Care}

Mice were obtained from Beijing HFK Bioscience Co., Ltd (China) and raised in a specific pathogen-free environment. All animal studies were approved by the Institutional Animal Care and Use Committee, National Center for Nanoscience \& Technology (IACUC, NCNST), and were performed in accordance to the prescribed procedures.

\section{Statistical Analysis}

At least 3 internal technical repeats were performed for each experiment. Data were presented as mean \pm standard deviation (Mean $\pm \mathrm{SD}$ ).

\section{Data Availability}

The data that support the finding of this study are available from the corresponding author on reasonable request. The data (antibacterial activities and biocompatibility of the commonly used antibiotics) that support the findings of this study are available from the TOXNET database (http: //toxnet.nlm.nih.gov/) (no accession code required). 

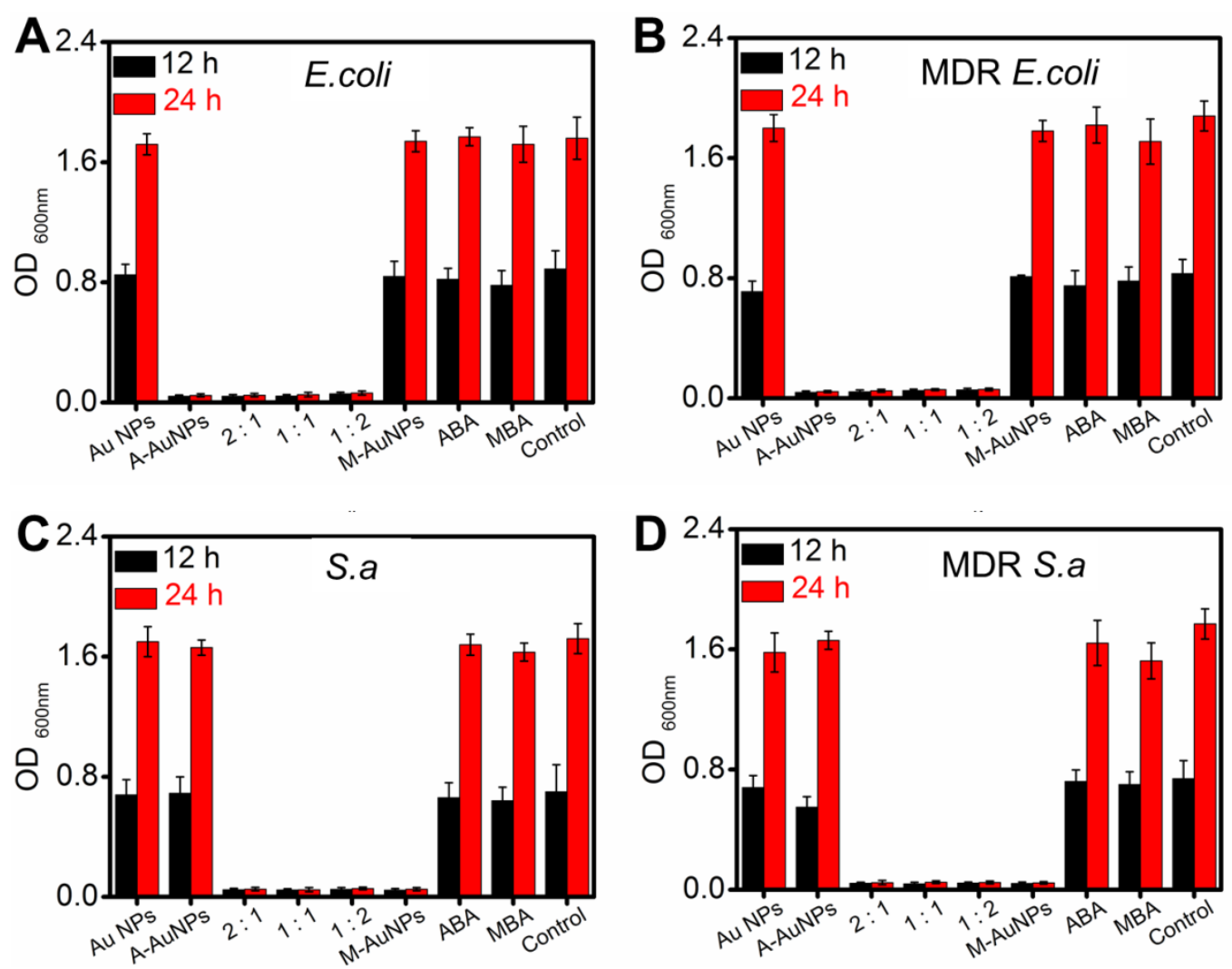

Figure S1. Antibacterial activity of the AuNPs modified by different ligands and ligand combinations. The $\mathrm{OD}_{600 \mathrm{~nm}}$ of bacterial suspensions treated by AuNPs (128 $\mu \mathrm{g} / \mathrm{mL})$, ABA $(128 \mu \mathrm{g} / \mathrm{mL})$, MBA $(128 \mu \mathrm{g} / \mathrm{mL})$, A-AuNPs $(12 \mu \mathrm{g} / \mathrm{mL})$, M-AuNPs $(12 \mu \mathrm{g} / \mathrm{mL})$, and A/M-AuNPs $(12 \mu \mathrm{g} / \mathrm{mL})$ with different ligand ratios are measured to illustrate the growth of (A) E. coli, (B) MDR E. coli, (C) S. $a$, and (D) MDR S. $a$. The bacteria suspension treated by LB medium is set as a control. The bars represent the average results of three parallel samples, and the error bars indicate one standard deviation of the means.
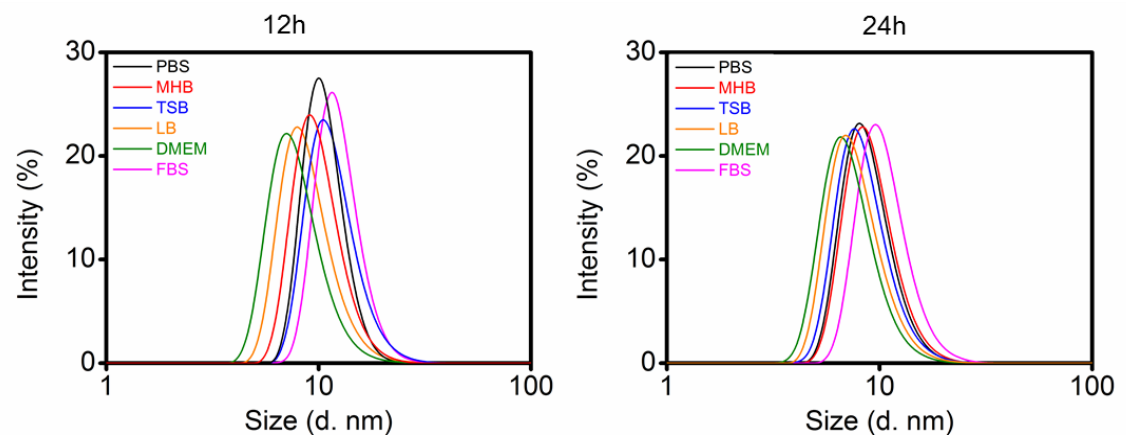

Figure S2. Stability of A/M-AuNPs (A) DLS analysis of the A/M-AuNPs incubated in different media for $12 \mathrm{~h}$. (B) DLS analysis of the A/M-AuNPs incubated in different media for $24 \mathrm{~h}$. 


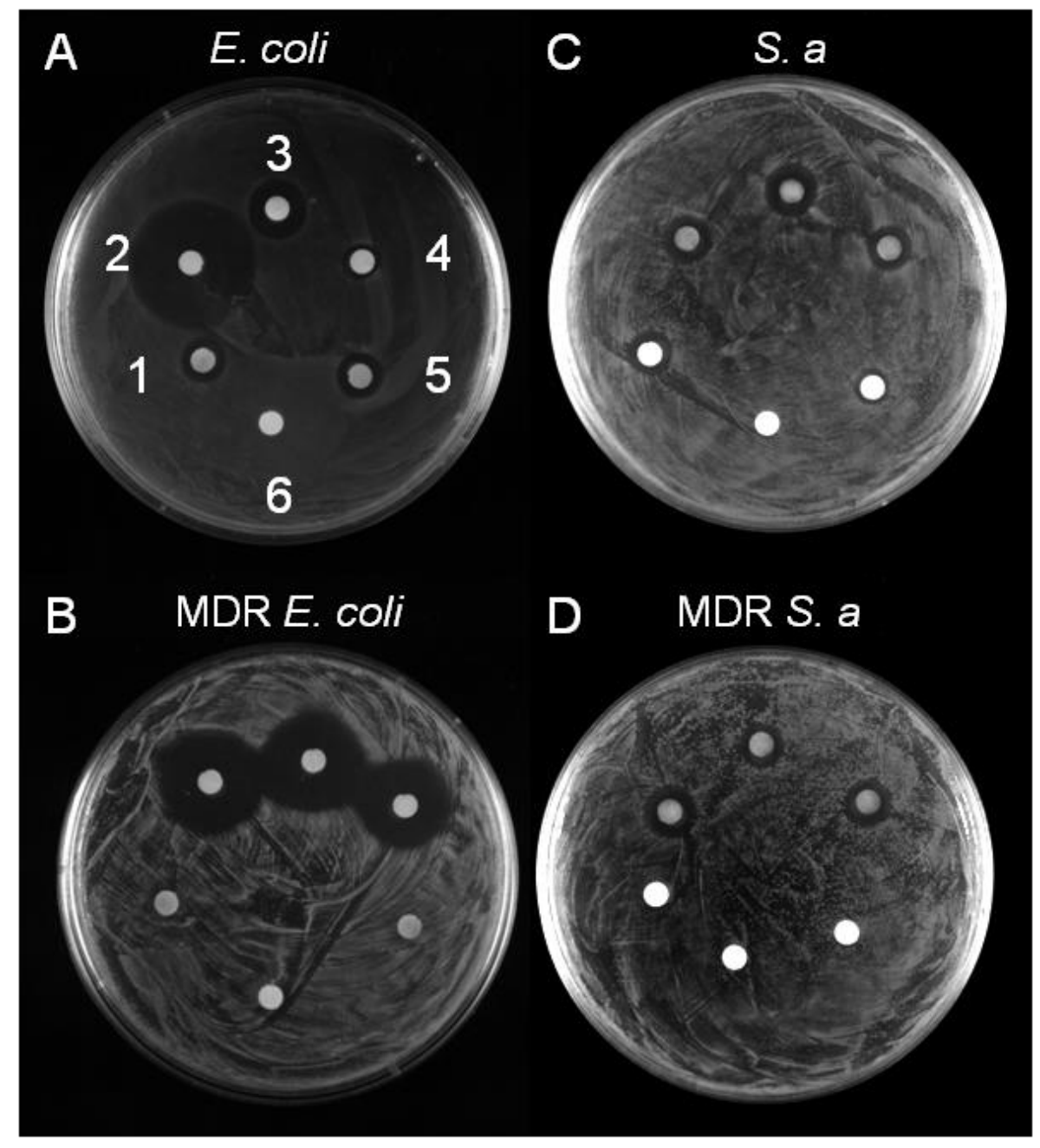

Figure S3. Evaluation of the antimicrobial activity of A/M-AuNPs and antibiotics by disk diffusion assay. The assay shows the antimicrobial activities of A/M-AuNPs and antibiotics against Gram-negative (G-) bacteria (A) E. coli (B) MDR E. coli and Gram-positive (G+) bacteria (C) $S$. a (D) MDR $S$. a. (1, Ampicillin $(4 \mu \mathrm{g} / \mathrm{mL}$ for $E$. coli, $1 \mu \mathrm{g} / \mathrm{mL}$ for $S . a, 64 \mu \mathrm{g} / \mathrm{mL}$ for MDR E. coli and MDR $S . a)$. 2, the molar ratio of ABA and MBA 2:1 (6 $\mu \mathrm{g} / \mathrm{mL}$ for $\mathrm{G}+$ and $9 \mu \mathrm{g} / \mathrm{mL}$ for G-). 3, the molar ratio of ABA and MBA 1:1 (6 $\mu \mathrm{g} / \mathrm{mL}$ for $\mathrm{G}+$ and $9 \mu \mathrm{g} / \mathrm{mL}$ for $\mathrm{G}-) .4$, the molar ratio of ABA and MBA 1:2 (6 $\mu \mathrm{g} / \mathrm{mL}$ for $\mathrm{G}+$ and $9 \mu \mathrm{g} / \mathrm{mL}$ for G-). 5, Ofloxacin $(2 \mu \mathrm{g} / \mathrm{mL}$ for $E$. coli and $S$. $a ; 64 \mu \mathrm{g} / \mathrm{mL}$ for MDR E. coli and MDR S. a). 6, control). 


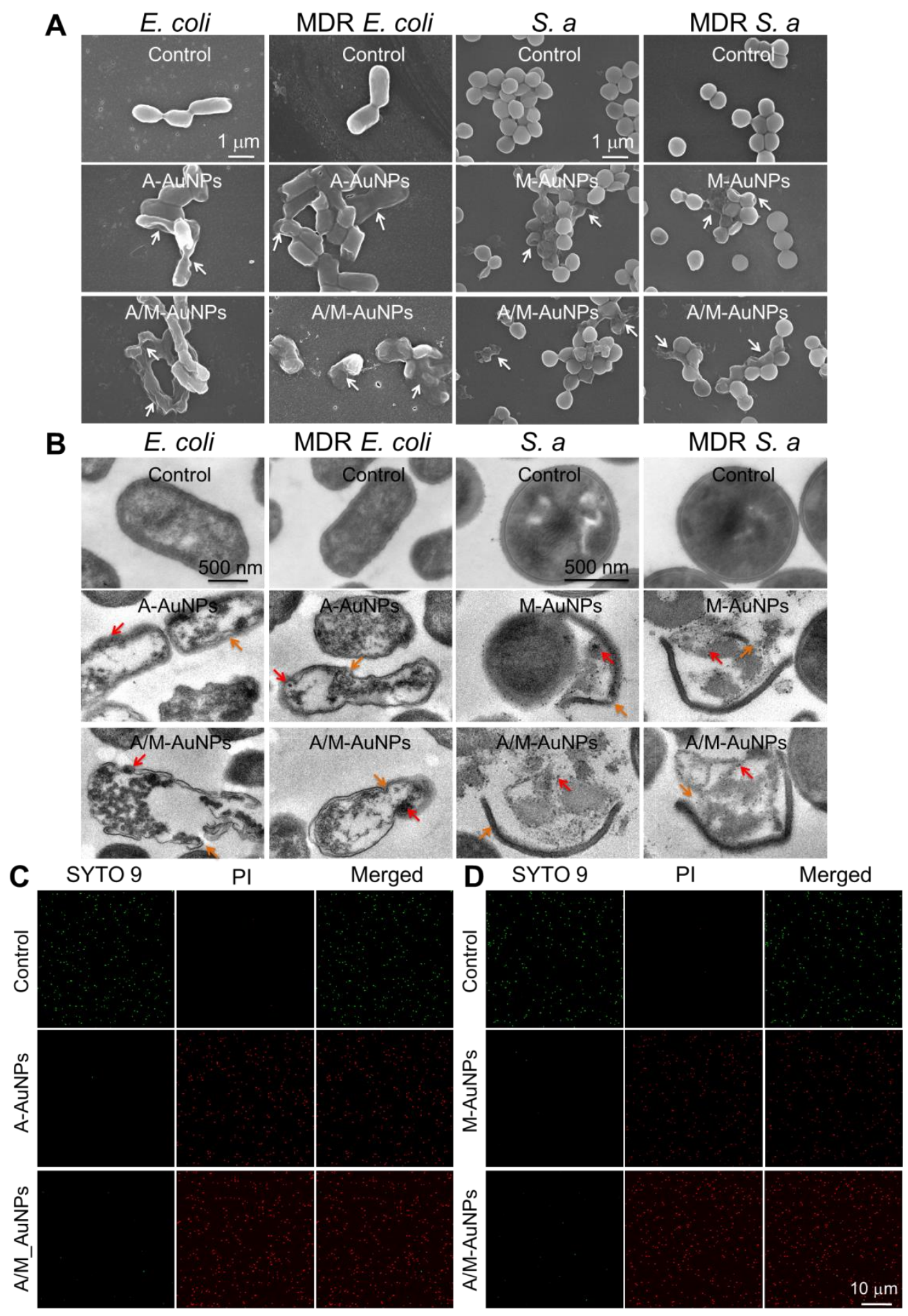

Figure S4. Different phenylboronic acid-derivative-modified AuNPs-induced disruption of bacterial cell wall. (A) SEM and (B) TEM images of the bacteria incubated with A-AuNPs, M-AuNPs, or A/M-AuNPs. White arrows point to the collapsed bacterial cell wall. Red arrows indicate the nanoparticles located in the cytosol of the bacteria. Orange arrows indicate the blurred or disappeared bacterial cell wall. LSCM images of (C) E. coli and (D) $S$. $a$ incubated with a mixture of SYTO 9 (green) and PI (red) dyes to monitor the phenylboronic acid-derivative-modified $\mathrm{Au}$ NPs-induced permeability of the bacterial cell wall. 

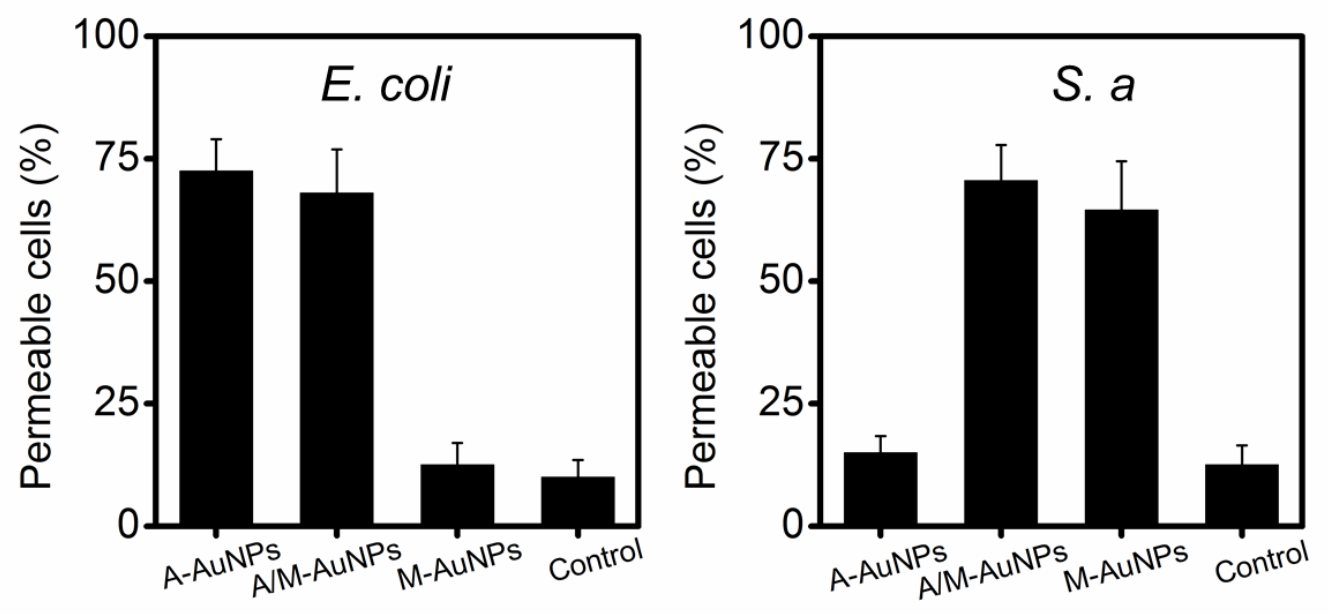

Figure S5. Characterization of the AuNPs-induced permeability of bacterial cell membranes via PI.

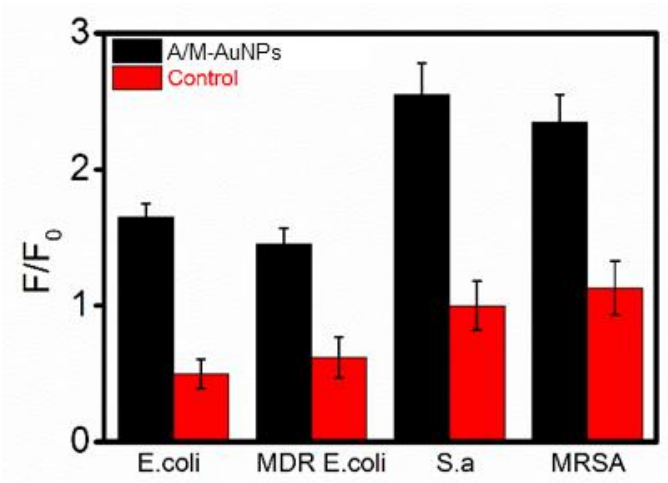

Figure S6. Membrane potential of different bacteria treated by A/M-AuNPs. LB media is set as a control. 

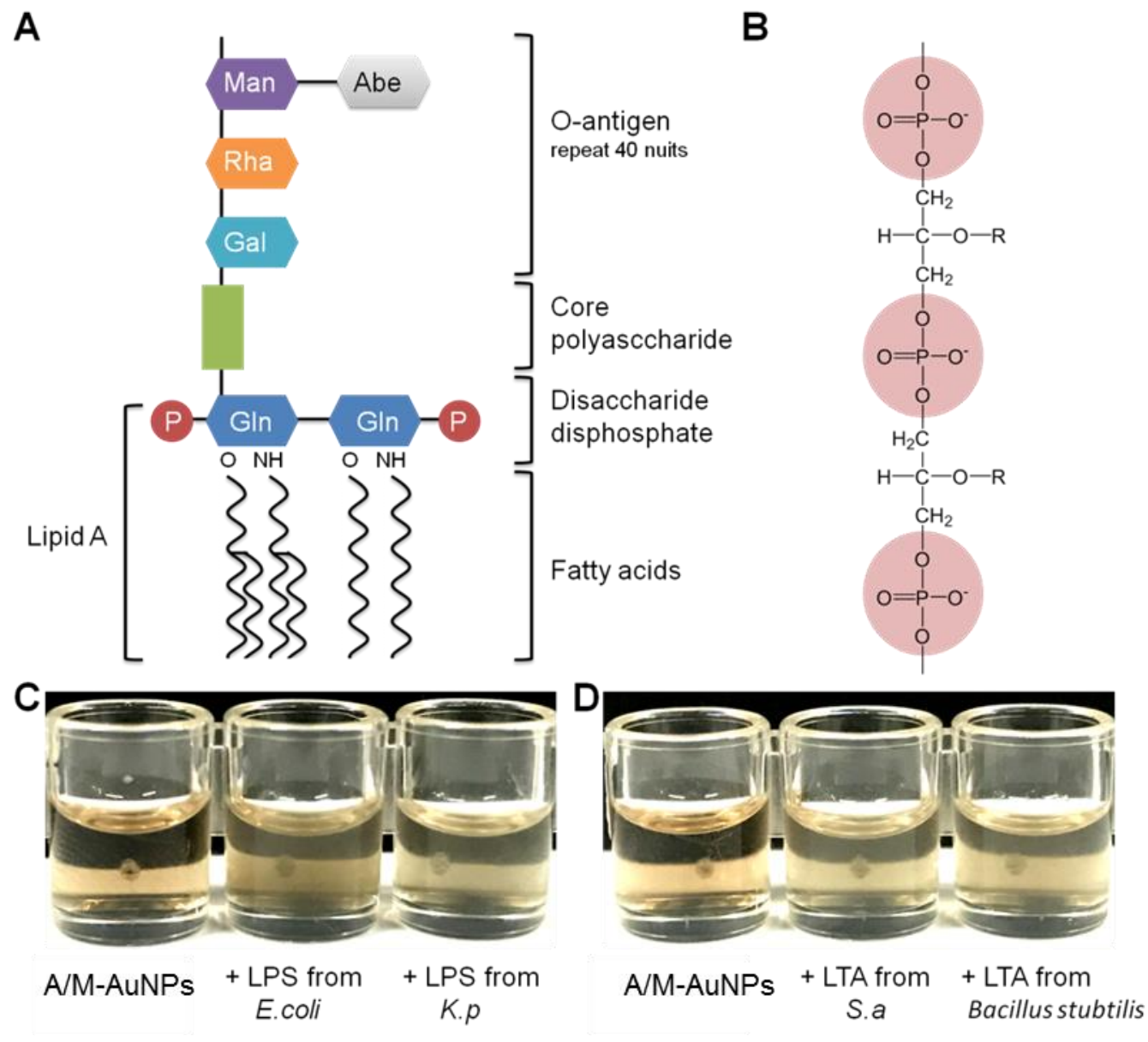

Figure S7. Structure of LPS and LTA and the photographs of the A/M-AuNPs solutions incubated with LPS or LTA purified from different bacteria. (A) Structure of LPS, Man: Mannose, Rha: L(+)-Rhamnose monohydrate, Gal: galactose, Abe: abequose, Gln: N-acrtylglucosamine, and P: phosphonates. (B) Structure of LTA, phosphonates are marked by pink circle and $\mathrm{R}$ indicates the $\mathrm{D}$-alanine or glucose. Images show A/M-AuNPs incubated with (C) LPS from different bacteria (purified LPS from E. coli or $K . p$ ) or (D) LTA from different bacteria (purified from $S$. $a$ or Bacillus subtilis). 

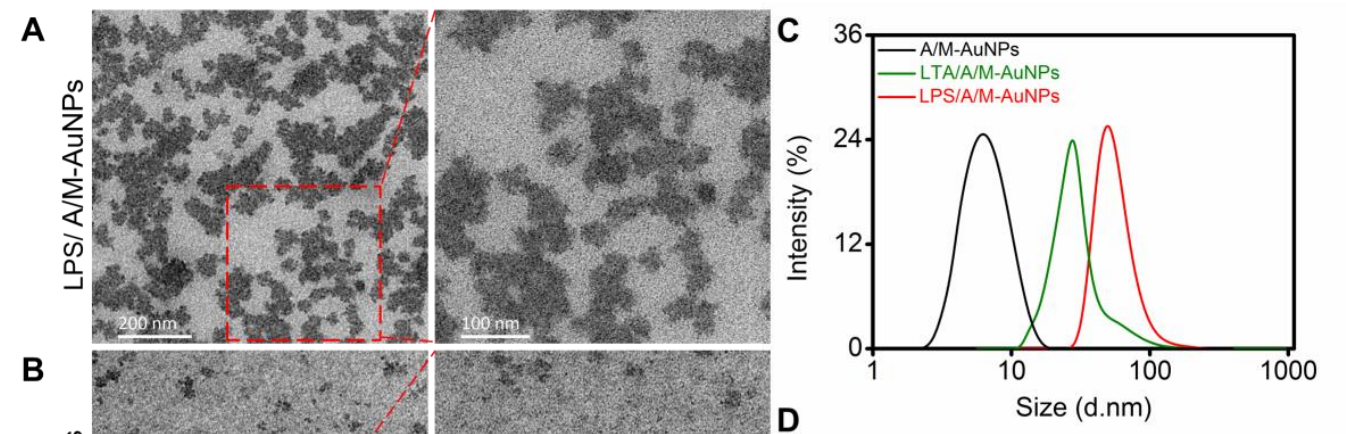

B
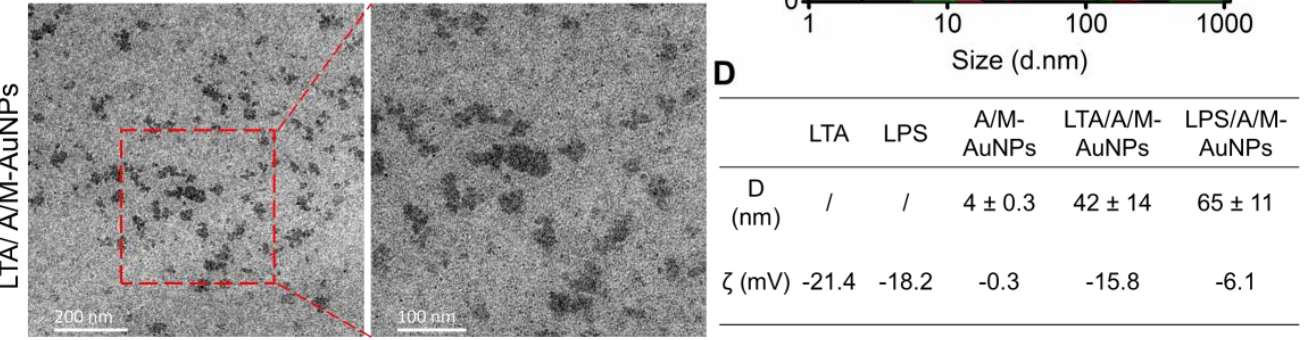

$\zeta(\mathrm{mV})-21.4-18.2 \quad-0.3 \quad-15.8 \quad-6.1$

Figure S8. Characterization of A/M-AuNPs interacted with LPS and LTA. The morphological changes of A/M-AuNPs incubated with (A) LPS and (B) LTA are observed by TEM images. (C) Average size and DLS analysis of the A/M-AuNPs incubated with LPS and LTA. (D) Zeta potential of the LPS, LTA, A/M-AuNPs and A/M-AuNPs incubated with LPS and LTA, respectively. 


\section{A-AuNPs+LPS}

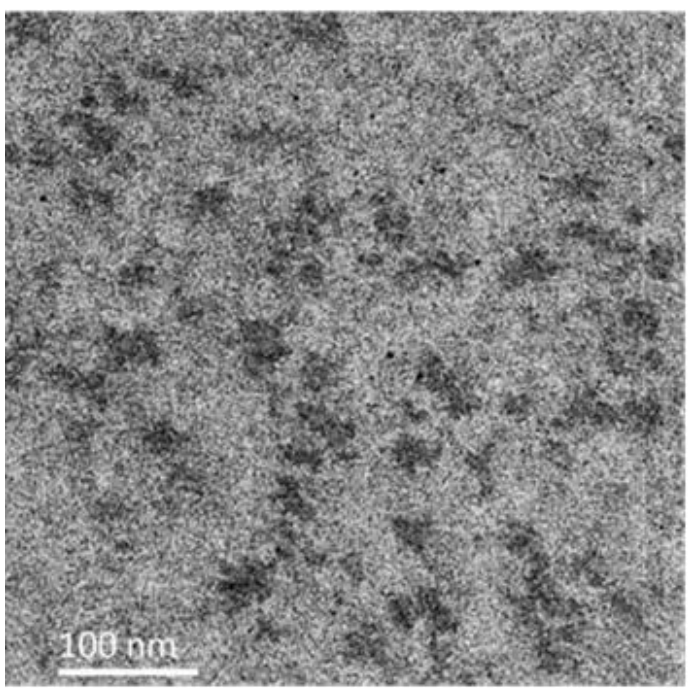

M-AuNPs+LPS

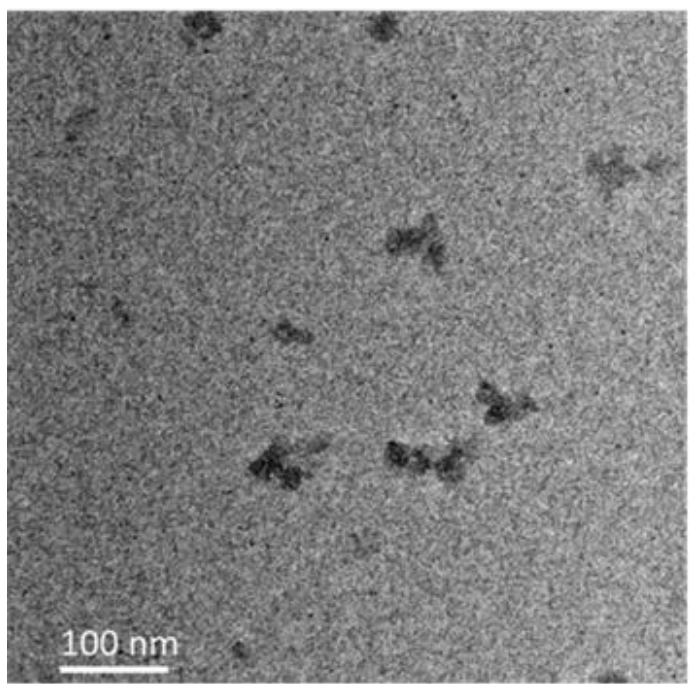

Figure S9. Characterization of A-AuNPs or M-AuNPs interacted with LPS and LTA.
A-AuNPs+LTA

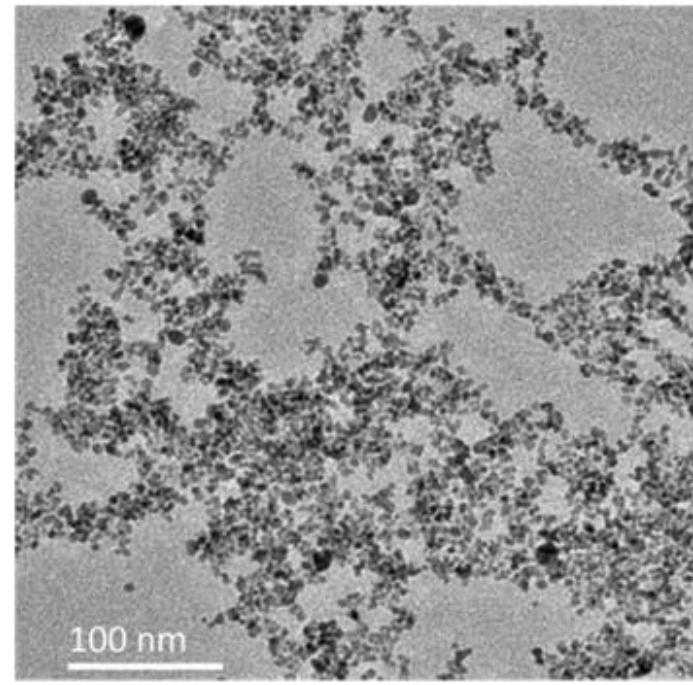

M-AuNPs+LTA

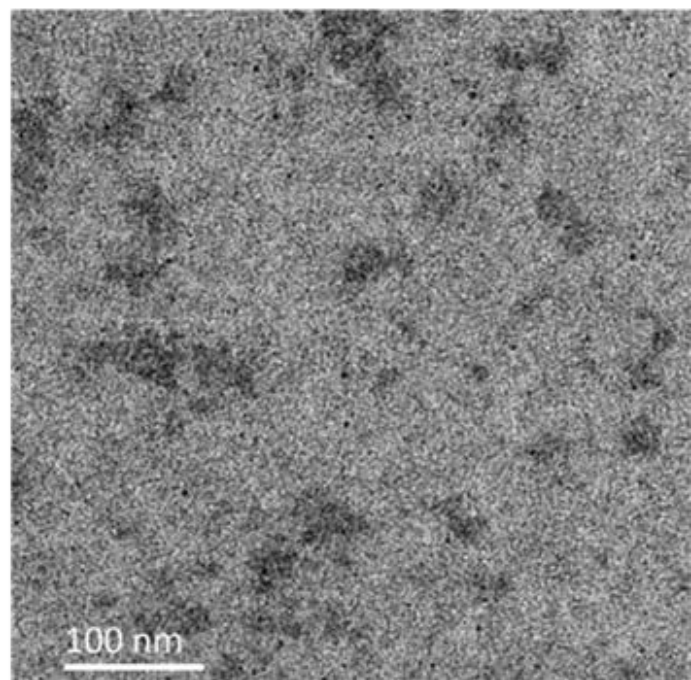

$100 \mathrm{~nm}$ 

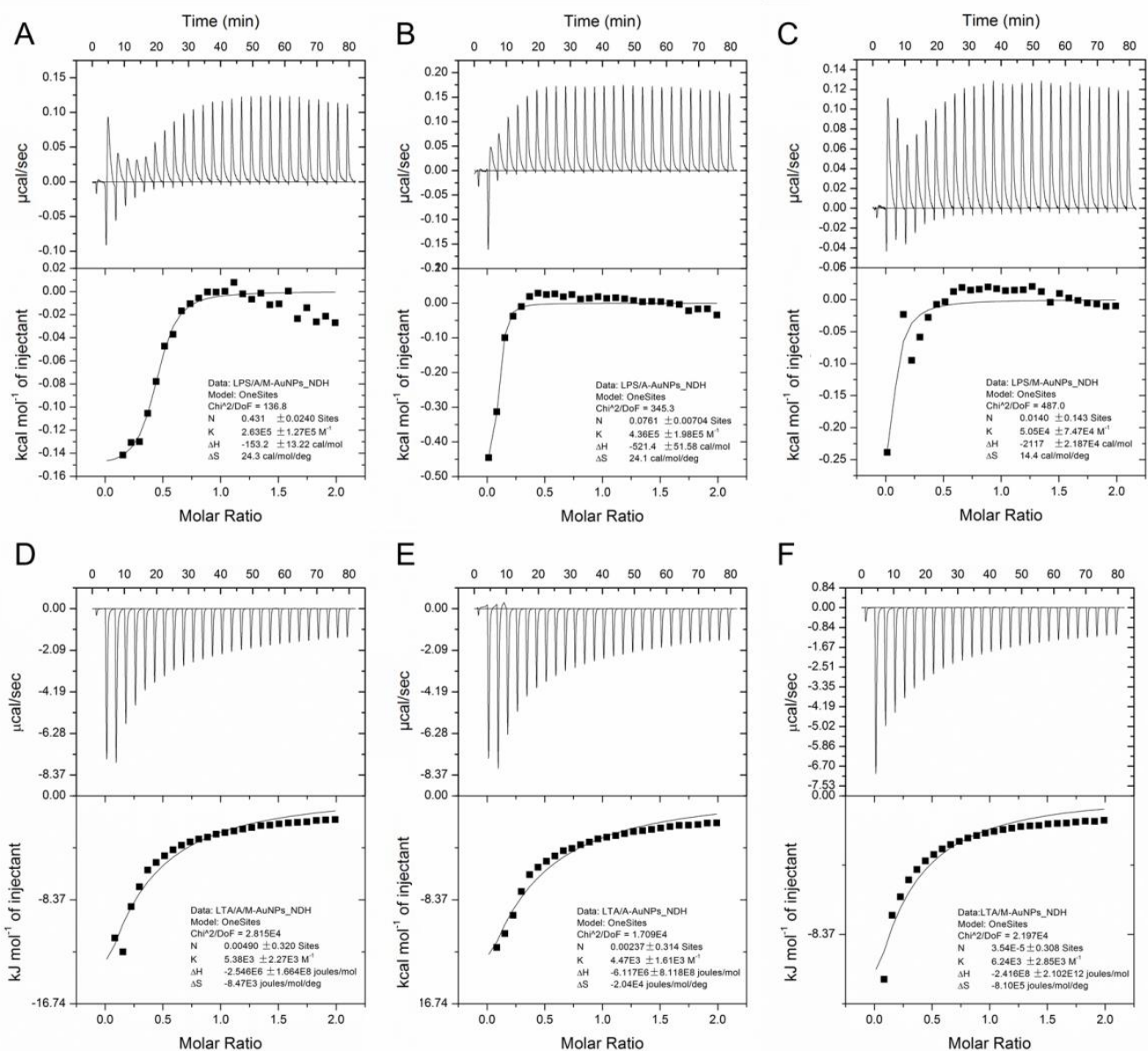

Figure S10. ITC data recorded for AuNPs and polysaccharide base interactions. Curves correspond to LPS interactions with (A) A/M-AuNPs, (B) A-AuNPs, and (C) M-AuNPs, respectively. Curves correspond to LTA interactions with (D) A/M-AuNPs, (E) A-AuNPs, and (F) M-AuNPs, respectively.
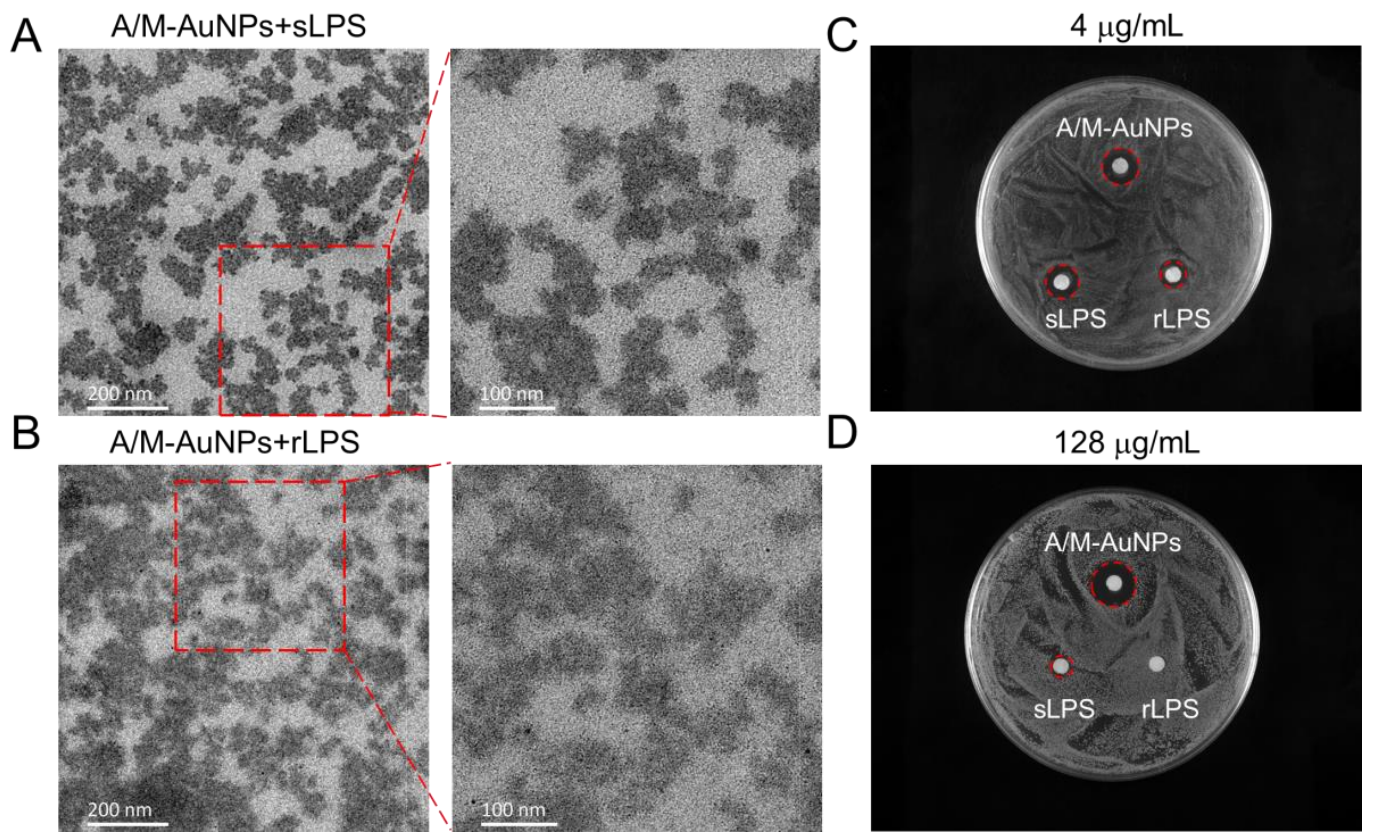
Figure S11. Characterization of A/M-AuNPs interacted with sLPS and rLPS. The morphological changes of A/M-AuNPs incubated with (A) sLPS and (B) sLPS are observed by TEM images. Inhibition zone assay shows the purified rLPS or sLPS influence the antibacterial activity of A/M-AuNPs against (C) E. coli or (D) $S$. $a$.

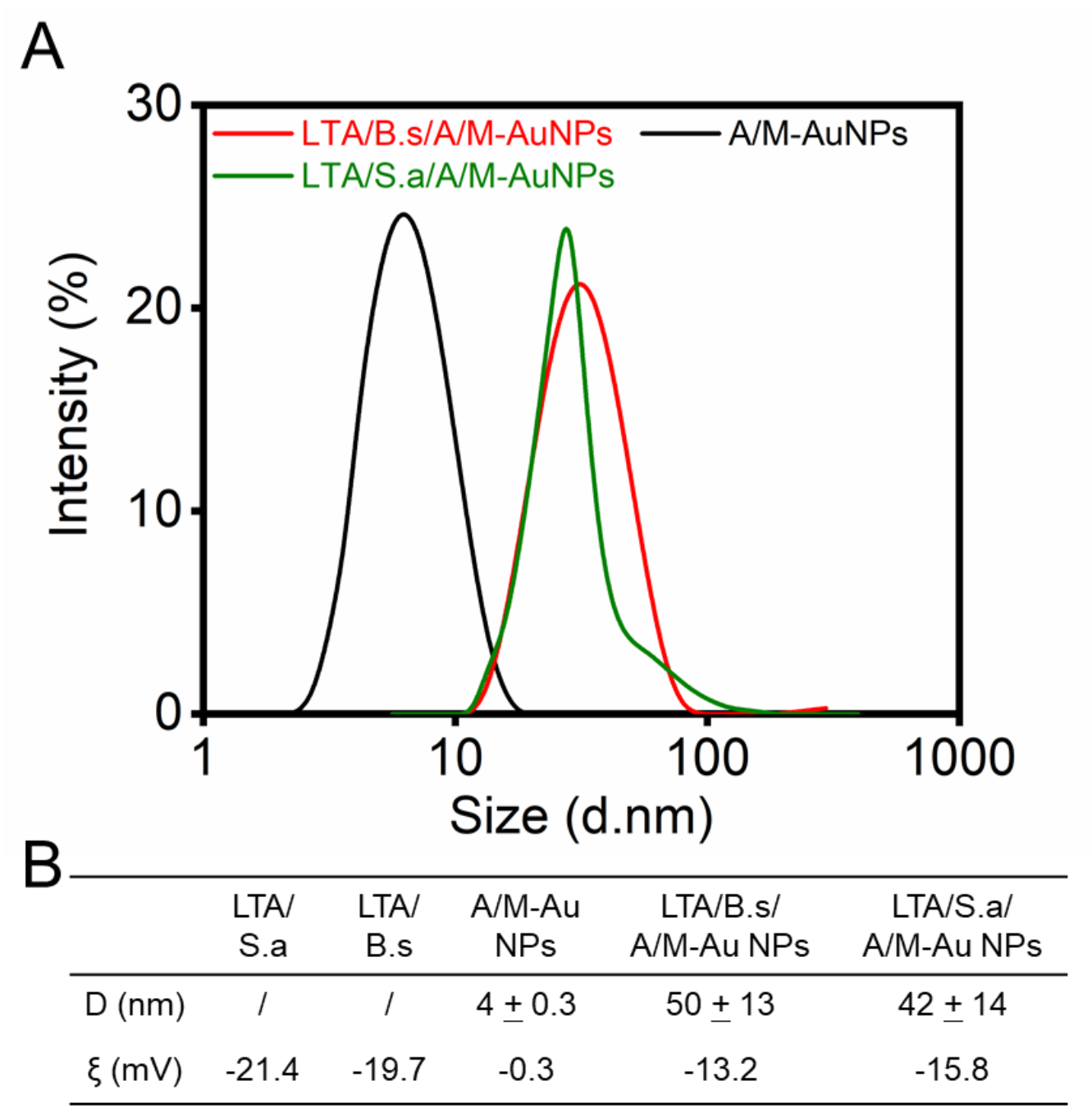

Figure S12. Characterization of A/M-AuNPs interacted with LTA from Bacillus stubtilis and $S$. $a$ for 12 h. (A) Average size and (B) DLS analysis of the A/M-AuNPs incubated with LTA from Bacillus stubtilis (LTA/B. s/A/M-AuNPs) and LTA from $S$. $a$ (LTA/S. $a / \mathrm{A} / \mathrm{M}-\mathrm{AuNPs})$. The data related to $S . a$ come from Figure 8C-D.

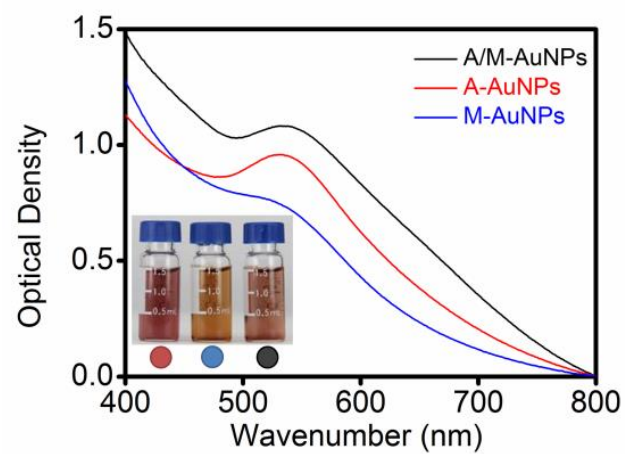


Figure S13. Characteristics of AuNPs. UV-visible spectrum of A-AuNPs, M-AuNPs, and A/M-AuNPs. The inside images are the photographs of the A-AuNPs, M-AuNPs, and A/M-AuNPs.
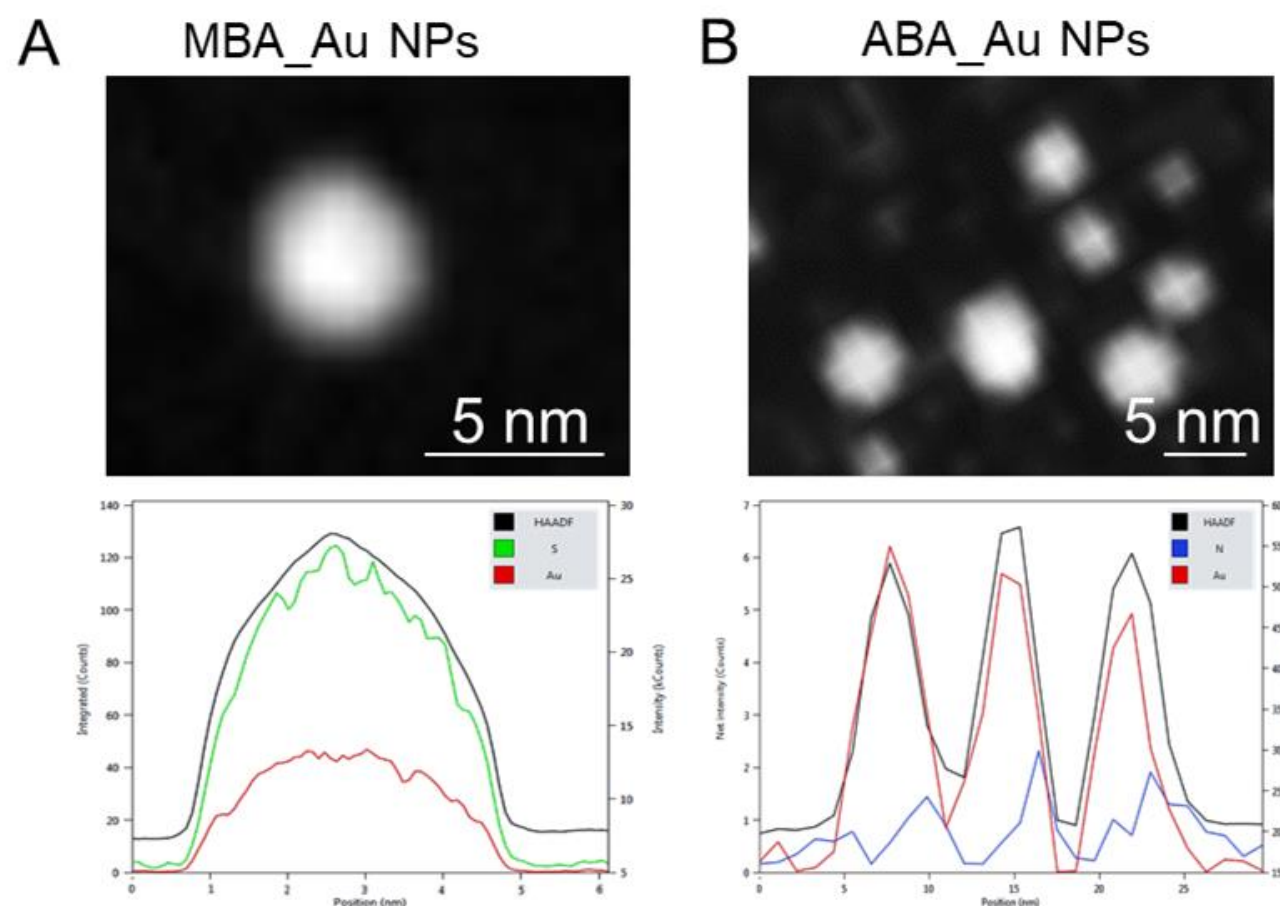

Figure S14. Energy-dispersive spectroscopy (EDS) mapping of (A) M-AuNPs and (B) A-AuNPs by TEM. 


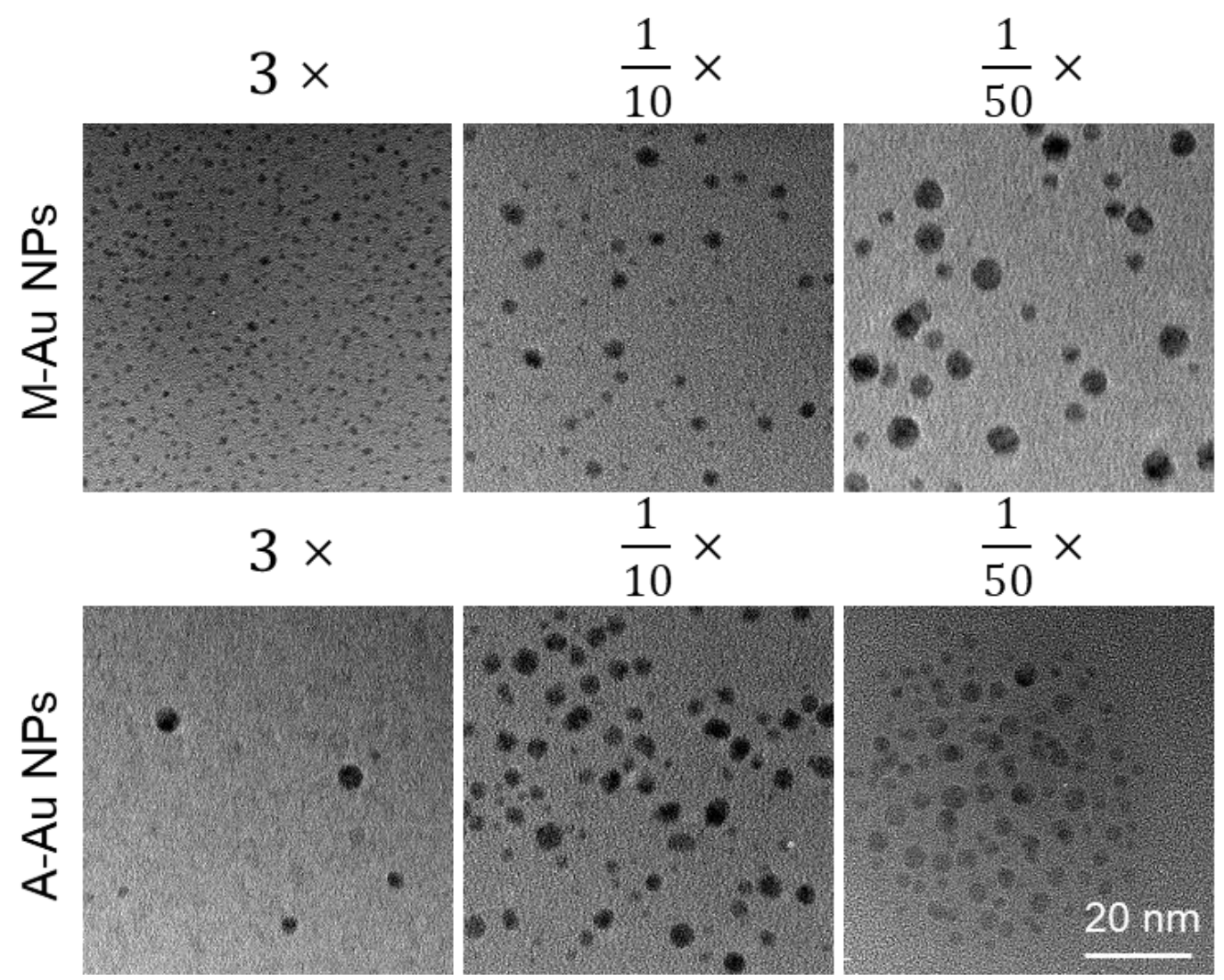

Figure S15. TEM of AuNPs modified with different concentrations of MBA or ABA molecules respectively. 


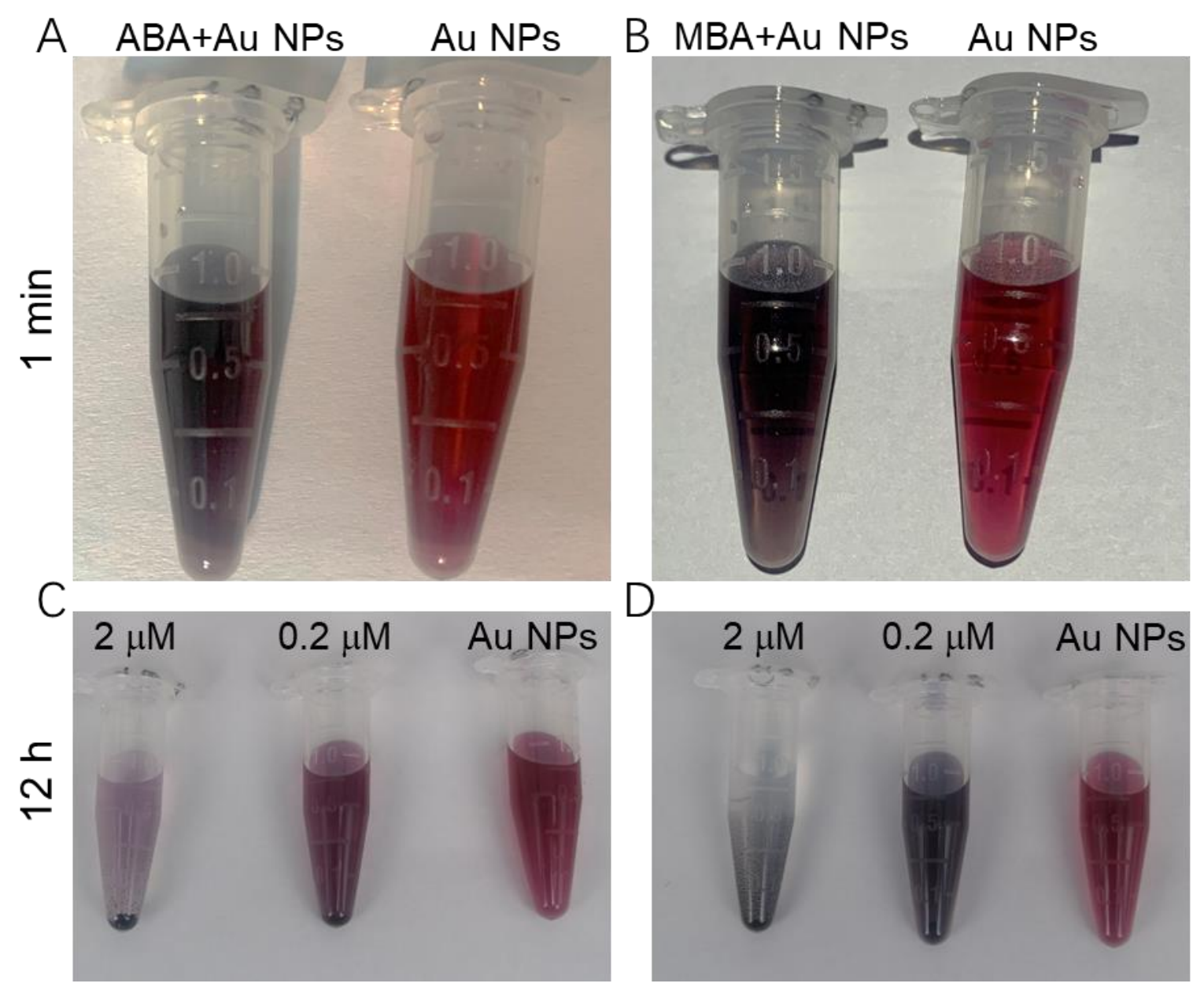

Figure S16. Images of AuNPs synthesized by sodium citrate reduction method (form bare AuNPs) and incubated with different concentrations of ligand molecules. (A) The appearance of bare AuNPs solution with the addition of $5 \mathrm{mM}$ ABA. (B) The appearance of bare AuNPs solution with the addition of $5 \mathrm{mM}$ MBA. (C) The appearance of bare AuNPs incubated with different concentrations of ABA for $12 \mathrm{~h}$. (D) The appearance of bare AuNPs incubated with different concentrations of MBA for $12 \mathrm{~h}$. 

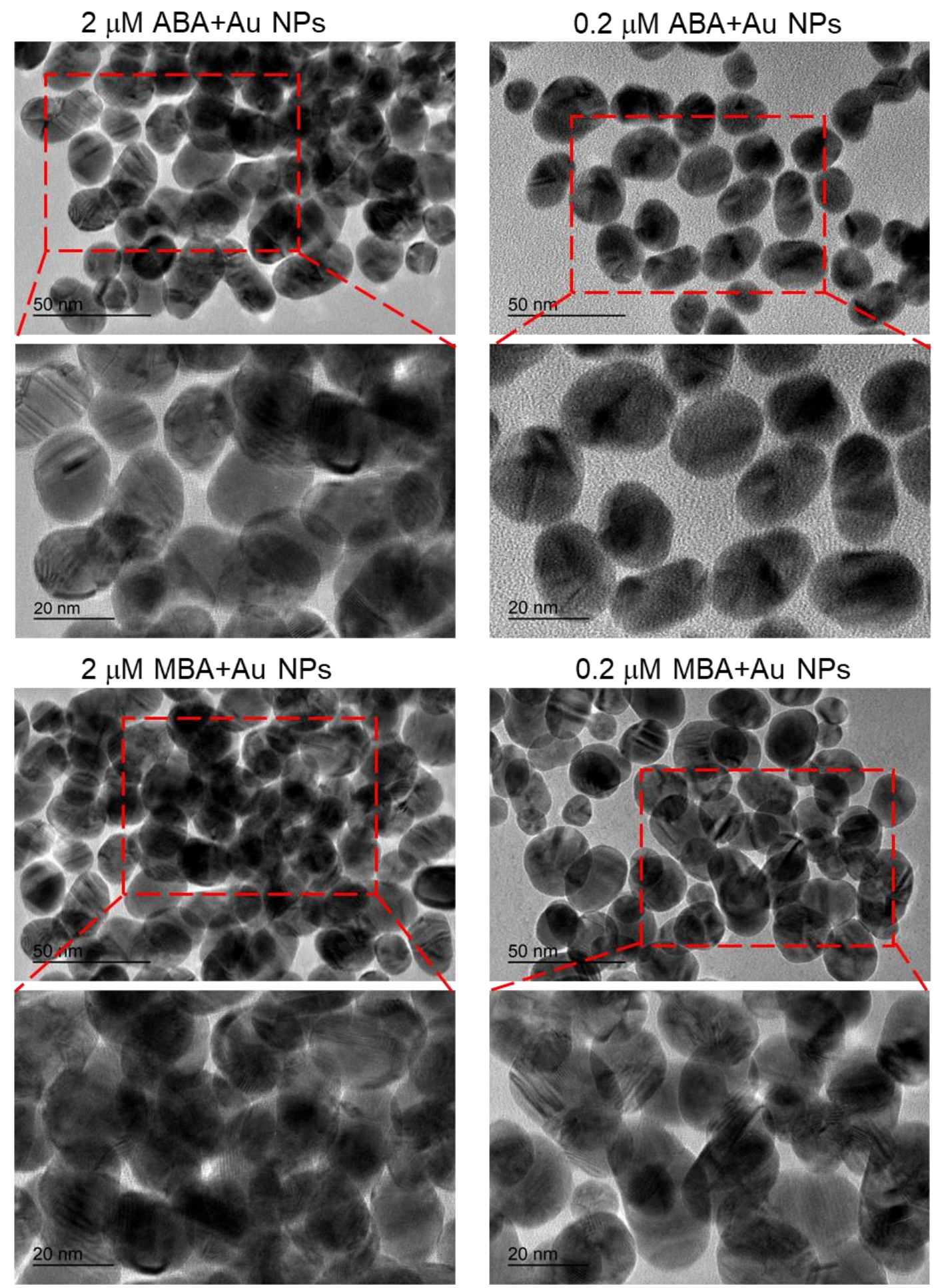

Figure S17. TEM images of AuNPs synthesized by sodium citrate reduction method and incubated with different concentrations of MBA or ABA molecules. 


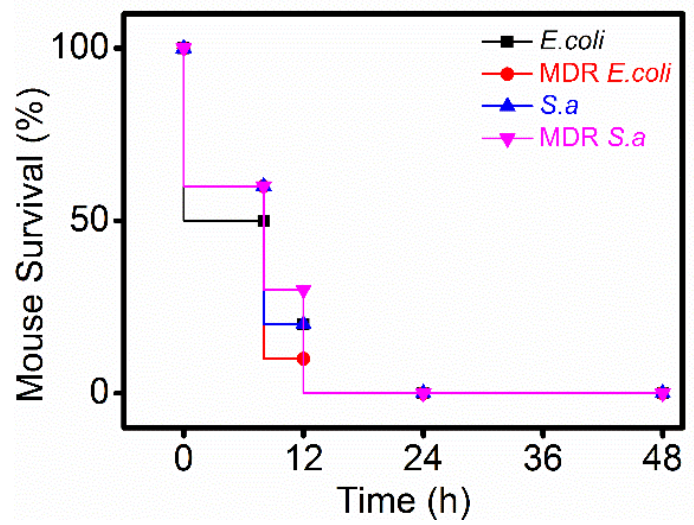

Figure S18. Survival ratios of the bacterial infected mice treated by AuNPs.

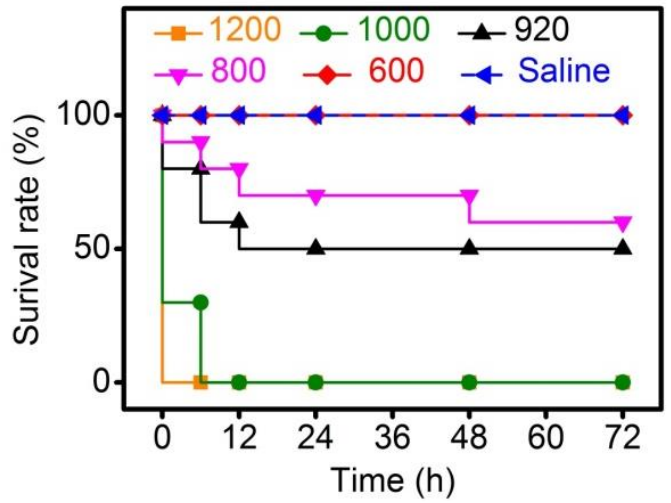

Figure 19. Survival of mice treated by different concentrations of A/M-AuNPs $72 \mathrm{~h}$ post-administration. Saline serves as a negative control with the same volume. 
Table S1. Strains of bacteria used in this study.

\begin{tabular}{|c|c|}
\hline Strains & Source \\
\hline \multicolumn{2}{|l|}{ G- bacteria } \\
\hline Escherichia coli (E. coli) & ATCC 25922 \\
\hline $\begin{array}{c}\text { Multidrug-resistant Escherichia coli (MDR } \\
\text { E. coli) }\end{array}$ & ATCC25922 \\
\hline Klebsiella pneumoniae $(K . p)$ & ATCC 13883 \\
\hline Klebsiella pneumonia with capsule $(K . p+)$ & ATCC 1003 \\
\hline Pseudomonas aeruginosa (P. a) & ATCC 27853 \\
\hline \multicolumn{2}{|l|}{ G+ bacteria } \\
\hline Staphylococcus aureus ypfP mutant (SA113) & ATCC 35556 \\
\hline Staphylococcus aureus (S. a) & ATCC 29213 \\
\hline Staphylococcus epidermidis (S. e) & ATCC 12228 \\
\hline Enterococcus faecalis (E.f) & ATCC 29212 \\
\hline
\end{tabular}

ATCC, American Type Culture Collection

Table S2. Antibacterial activity of MBA, ABA and their different isomers and naked AuNPs indicated by MIC $(\mu \mathrm{g} / \mathrm{mL})$. Details of the bacterial strains are listed in Table S1.

\begin{tabular}{cccccccc}
\hline & & $3 \mathrm{M}$ & $4 \mathrm{M}$ & $2 \mathrm{~A}$ & $3 \mathrm{~A}$ & $4 \mathrm{~A}$ & $\mathrm{Au} \mathrm{NPs}$ \\
\hline $\begin{array}{c}\text { G- } \\
\text { bacteria }\end{array}$ & $\begin{array}{c}\text { E. coli } \\
\text { MDR }\end{array}$ & $>512$ & $>512$ & $>512$ & $>512$ & $>512$ & $>512$ \\
& E. coli & $>512$ & $>512$ & $>512$ & $>512$ & $>512$ & $>512$ \\
\hline $\begin{array}{c}\text { G+ } \\
\text { bacteria }\end{array}$ & S. $a$ & $>512$ & $>512$ & $>512$ & $>512$ & $>512$ & $>512$ \\
\hline
\end{tabular}

Table S3. Antibacterial activity of MBA, ABA and their different isomers-capped gold nanoparticles indicated by MIC $(\mu \mathrm{g} / \mathrm{mL})$. Details of the bacterial strains are listed in Table $\mathrm{S} 1$.

3M-AuNPs 4M-AuNPs 2A-AuNPs 3A-AuNPs 4A-AuNPs

\begin{tabular}{ccccccc}
\hline $\begin{array}{c}\text { G- } \\
\text { bacteria }\end{array}$ & $\begin{array}{c}\text { E. coli } \\
\text { MDR }\end{array}$ & $>64$ & $>64$ & 3 & 2 & 4 \\
\hline E. coli & $>64$ & $>64$ & 8 & 10 & 6 \\
\hline $\mathrm{G}^{+}$ & S. $a$ & 6 & 6 & $>64$ & $>64$ & $>64$ \\
\hline
\end{tabular}




\begin{tabular}{lllllll}
\hline bacteria & $\begin{array}{c}\text { MDR } \\
\text { S. } a\end{array}$ & 6 & 6 & $>64$ & $>64$ & $>64$ \\
\hline
\end{tabular}

Table S4. Components of the ABA and MBA co-modified Au NPs.

\begin{tabular}{lccc}
\hline Materials & $\begin{array}{c}\text { Molar ratio of } \\
\text { nitrogen to Au in } \\
\text { NPs }\end{array}$ & $\begin{array}{c}\text { Molar ratio of } \\
\text { sulfur to Au in } \\
\text { NPs }\end{array}$ & $\begin{array}{c}\text { Molar ratio of } \\
\text { nitrogen to sulfur }\end{array}$ \\
\hline $\begin{array}{c}\text { A/M-AuNPs } \\
(75: 25)\end{array}$ & $1.37: 1$ & $0.69: 1$ & $1.98: 1(\approx 2: 1)$ \\
$\begin{array}{c}\text { A/M-AuNPs } \\
(50: 50)\end{array}$ & $3.28: 1$ & $3.34: 1$ & $0.98: 1(\approx 1: 1)$ \\
$\begin{array}{c}\text { A/M-AuNPs } \\
(25: 75)\end{array}$ & $2.32: 1$ & $1.22: 1$ & $0.52: 1(\approx 1: 2)$ \\
\hline
\end{tabular}

Table S5. Dissociation constant of AuNPs-polysaccharides interactions.

\begin{tabular}{cccc}
\hline $\begin{array}{c}\text { Dissociation Constant }\left(\mathrm{K}_{\mathrm{d}}\right) \\
/ \mu \mathrm{M}\end{array}$ & A/M-AuNPs & A-AuNPs & M-AuNPs \\
\hline LPS & 3.80 & 2.29 & 143.26 \\
LTA & 200.02 & 223.71 & 160.25 \\
\hline
\end{tabular}

Table S6. Components of the A-AuNPs and M-AuNPs

\begin{tabular}{ccc}
\hline Materials & $\begin{array}{c}\text { Molar ratio of nitrogen to } \\
\text { Au in NPs }\end{array}$ & $\begin{array}{c}\text { Molar ratio of sulfur to Au in } \\
\text { NPs }\end{array}$ \\
\hline A-AuNPs & $0.76: 1$ & $/$ \\
M-AuNPs & $/$ & $1.88: 1$ \\
\hline
\end{tabular}

Table S7. Antibacterial activities and biocompatibility of the commonly used antibiotics and $\mathrm{A} / \mathrm{M}-\mathrm{AuNPs}$ are indicated by $\mathrm{MIC}$ and $\mathrm{LD}_{50 \text {,i.v. }}$ respectively.

\begin{tabular}{lllllll}
\hline & & \multicolumn{4}{c}{ Antibacterial activity } & \\
\cline { 3 - 6 } Materials & CAS & E. coli & $\begin{array}{l}\text { MDR } \\
\text { E. coli }\end{array}$ & S. $a$ & $\begin{array}{l}\text { MDR } \\
\text { S. } a\end{array}$ & $\begin{array}{l}\text { (mg,i.v. } \\
\text { (mg) }\end{array}$ \\
\hline Ampicillin & $69-53-4$ & 4 & $>64$ & 1 & $>64$ & 366 \\
Ofloxacin & $82419-36-1$ & 2 & $>64$ & 1 & $>64$ & 208 \\
Vancomycin & $1404-90-6$ & $>64$ & $>64$ & 1 & 2 & 430 \\
Norfloxacin & $70458-96-7$ & 2 & $>64$ & 2 & $>64$ & 222 \\
Gentamycin & $1403-66-3$ & 0.1 & 64 & 1.5 & 16 & 51
\end{tabular}




\begin{tabular}{ccccccc} 
A/M-AuNPs & $/$ & 3 & 6 & 6 & 6 & 920 \\
\hline Data from the TOXNET database (http: //toxnet.nlm.nih.gov/) &
\end{tabular}

Data from the TOXNET database (http: //toxnet.nlm.nih.gov/) 


\section{References}

1 M. C. Daniel, J. Ruiz, S. Nlate, J. C. Blais, D. Astruc. J Am Chem Soc, 2003, 125, 2617-2628.

2 J. R. Morones-Ramirez, J. A. Winkler, C. S. Spina, J. J. Collins. Sci. Transl. Med. 2013, 5,181-190. 